\title{
Automatic Section Control Technologies and GPS Auto-guidance Systems Adoption in Cotton Production
}

\author{
Brittani Edge ${ }^{1}$, Margarita Velandia ${ }^{2}$, Christopher Boyer ${ }^{2}$, James Larson ${ }^{2}$, Dayton Lambert ${ }^{2}$, Roland Roberts ${ }^{2}$, \\ Bradley Wilson ${ }^{2}$, Michael Buschermohle ${ }^{3}$, Burton English ${ }^{2}$, Roderick Rejesus ${ }^{4} \&$ Larry Falconer $^{5}$ \\ ${ }^{1}$ Department of Agricultural and Consumer Economics, University of Illinois, Urbana-Champaign, Illinois, USA \\ ${ }^{2}$ Department of Agricultural \& Resource Economics, University of Tennessee, Knoxville, Tennessee, USA \\ ${ }^{3}$ Department of Biosystems Engineering and Soil Science, University of Tennessee, Knoxville, Tennessee, USA \\ ${ }^{4}$ Department of Agricultural and Resource Economics at North Carolina State University, Raleigh, North \\ Carolina, USA \\ ${ }^{5}$ Department of Agricultural Economics, Mississippi State University, Raleigh, Stoneville, Mississippi, USA \\ Correspondence: Margarita Velandia, University of Tennessee, 2621 Morgan circle, 314C Morgan Hall, \\ Knoxville, Tennessee 37996, USA. Tel: 1-865-974-7409. E-mail: mvelandia@utk.edu
}

$\begin{array}{lc}\text { Received: April 8, } 2018 & \text { Accepted: May 8, } 2018 \quad \text { Online Published: June 15, } 2018 \\ \text { doi:10.5539/jas.v10n7p282 } & \text { URL: https://doi.org/10.5539/jas.v10n7p282 }\end{array}$

\begin{abstract}
Using data from a survey of cotton producers in 14 US states, and a bivariate probit regression, this study examined the effects of the following measured parameters on the adoption of Automatic Section Control (ASC) technologies and GPS Auto-Guidance (AG) systems: age, education, farm size, field geometry, information sources, as well as the use of specific production practices and other Precision Agriculture (PA) technologies. Results suggest that younger, more educated producers, consulting farm dealers for information about PA technologies, using other PA technologies, and managing larger farming operations located in counties with more irregularly shaped fields are more likely to adopt ASC technologies and AG systems. Predicted adoption probabilities estimated using regression results suggest the use of other PA technologies and farm dealers as a source of precision farming information have the largest impact on the probability of adopting ASC by cotton farmers. Additionally, these results suggest farmers with operations in eastern Arkansas, western Tennessee, and a couple of counties in middle Tennessee are more likely to adopt ASC technologies. Producers in these regions had the highest percentages of users of other PA technologies and farm dealers to obtain PA information.
\end{abstract}

Keywords: adoption, automatic section control technologies, cotton, GPS auto-guidance systems

\section{Introduction}

Precision agriculture (PA) encompasses many technologies that use field-level data to improve input application efficiency (National Research Council, 1997). The application of an input such as seed or chemicals in sections of a field where that input has already been applied is one example of input application inefficiency (Larson, Velandia, Buschermohle, \& Westlund, 2016). Automatic section control (ASC) and GPS automated guidance (AG) systems are PA technologies that can reduce such inefficiency. During field operation, ASC turns planter/sprayer sections or rows off in areas of the field where inputs have been applied or on and off at headland turns, point rows, terraces, and/or waterways, reducing or eliminating input over application (Fulton, Mullenix, Brooke, Winstead, \& Ortiz, 2011). The AG systems complement ASC technologies by allowing producers to maintain a desired path through a field, eliminating application overlap and skips. AG systems also reduce fatigue from operating machinery, giving operators the ability to extend their working hours (Shockley, Dillon, \& Stomabaugh, 2011). Conversely, AG systems may reduce working hours by helping operators navigate through a field more efficiently (McDonald, 2015).

Previous studies have evaluated the economic benefits of ASC technologies and GPS guidance systems, including both manual and automated guidance systems (Batte \& Ehsani, 2006; Shockley et al., 2011; Shockley, Dillon, Stombaugh, \& Shearer, 2012; Velandia, Buschermohle, Larson, Thompson, \& Jernigan, 2013; Larson et al., 2016). Shockley et al. (2011) concluded that auto-steer navigation could increase the returns of a grain farmer in Kentucky by up to $0.9 \%$. Shockley et al. (2012) suggested the use of automatic section control 
technologies increases net returns for various field types and navigational scenarios. Furthermore, Velandia et al. (2013) found that savings associated with the adoption of automatic section control technologies for planters could be anywhere between $\$ 4$ and $\$ 26$ per ha depending on the percentage of fields classified as low, moderate, and high-double planted fields in a farming operation. While previous studies have evaluated the factors influencing the adoption of GPS guidance systems (Martin et al., 2007; Banerjee et al., 2008), no studies have evaluated the factors influencing the adoption of ASC technologies. Furthermore, no studies have evaluated the factors influencing the adoption of ASC and AG systems simultaneously, a desirable approach considering the complementary relationship between these technologies (Note 1). Thus, this study will address a gap in the literature by using a bivariate probit regression to evaluate factors influencing the adoption of these technologies.

Information about the factors that influence the adoption of ASC and AG systems would be beneficial to several groups, particularly producers and machinery dealers. The findings emanating from such research could be used in combination with decision-aid tools and extension publications to aid producers in the decision-making process. For example, output from the Automatic Section Control for Planters Cost Calculator (ASCCC) (Note 2) suggests that the impact of field geometry on the number of years necessary to pay back an investment in ASC for planters decreases as total farm size increases. That result could be validated by the results obtained from this study. In addition, results from this study can assist machinery dealers in identifying the locations of target clientele more likely to adopt ASC technologies and AG systems, and in developing marketing strategies that target those markets.

\section{Conceptual Framework}

Modeling the decision to adopt PA technologies begins with the assumption that farmers maximize the discounted expected benefits from production over a time horizon (Walton et al., 2008). Previous studies have used the random utility model framework to study adoption decisions (Rahm \& Huffman, 1984; Roberts et al., 2004; Larson et al., 2008; Walton et al., 2008; Jara-Rojas, Bravo-Ureta, Engler, \& Diaz, 2013; Lambert et al., 2014), where a producer adopts a technology when the expected utility of profits is higher for the adoption scenario compared to the non-adoption scenario. Let $E\left[U\left(\pi_{A G}\right)\right]\left(E\left[U\left(\pi_{N A G}\right)\right]\right)$ be the expected utility of profits of adopting (non-adopting) AG systems for producer $i$. Defining $U_{A G}^{*}=E\left[U\left(\pi_{A G}\right)\right]-E\left[U\left(\pi_{N A G}\right)\right]$, the expected utility-maximizing producer will choose to adopt AG systems if $U_{A G}^{*}>0$. Likewise, let $E\left[U\left(\pi_{A S C}\right)\right]$ $\left(E\left[U\left(\pi_{N A S C}\right)\right]\right)$ be the expected utility of profits of adopting (non-adopting) ASC technologies. Defining $U_{A S C}^{*}=E\left[U\left(\pi_{A S C}\right)\right]-E\left[U\left(\pi_{N A S C}\right)\right]$, the utility-maximizing producer will choose to adopt ASC when $U_{A S C}^{*}>0$.

As presented in Roberts et al. (2004) and Walton et al. (2008) and originally by McFadden (1974), the unobservable latent variables $U_{A G}^{*}$ and $U_{A S C}^{*}$ are hypothesized to be random functions of exogenous variables $x_{A G}$ and $x_{A S C}$, representing farmer and farm business characteristics:

$$
\begin{gathered}
U_{A G}^{*}=x_{A G}^{\prime} \beta_{A G}+\varepsilon_{A G} \\
U_{A S C}^{*}=x_{A S C}^{\prime} \beta_{A S C}+\varepsilon_{A S C}
\end{gathered}
$$

where, $\beta_{A G}$ and $\beta_{A S C}$ are vectors of unknown parameters associated with the explanatory variables and, $\varepsilon_{A G}$ and $\varepsilon_{A S C}$ are random disturbance terms. Although $U_{A G}^{*}$ and $U_{A S C}^{*}$ are unobservable, the decision to adopt any of these technologies can be observed such that:

for $j=\mathrm{ASC}, \mathrm{AG}$.

$$
y_{j}=\left\{\begin{array}{l}
1 \text { if } U_{j}^{*}>0 \\
0 \text { otherwise }
\end{array}\right.
$$

\section{Methods}

\subsection{Areas Surveyed and Questions Asked}

The data used in this study were obtained from the 2013 Southern Cotton Farm Survey mailed out in February 2013 to 13,566 cotton producers across 14 US states (Alabama, Arkansas, Florida, Georgia, Kansas, Louisiana, Mississippi, Missouri, North Carolina, Oklahoma, South Carolina, Tennessee, Texas, and Virginia). A total of 1,810 surveys were appropriate for analysis after eliminating those that were returned undeliverable or from producers who were no longer growing cotton, resulting in a 14\% response rate (Zhou et al., 2015). The survey followed the Dillman's Tailored Design Method (Dillman, 2000) by using reminder cards and a second mailing of surveys to those producers who did not respond to the first wave of surveys sent in February.

The survey was divided into four sections: "You and Your Farm," "General Questions about Precision Agriculture," "Variable Rate Application on Cotton," and "Information about Your Household." These sections contained questions about adoption and abandonment of PA technologies, sources used to obtain information 
about PA technologies, producer opinions about PA technologies' importance and profitability, and farm and producer characteristics.

Previous research suggests field geometry could affect the economic benefits associated with the adoption of ASC technologies and therefore the decision to adopt these technologies (Shockley et al., 2012; Smith, Dhuyvetter, Kastens, Kastens, \& Smith, 2013; Velandia et al., 2013; Larson et al., 2016). The survey did not include questions to assess farm field geometry; thus, secondary data were used to create two county-level field geometry measures. Perimeter $\left(p_{i}\right)$ and area $\left(a_{i}\right)$ field data used to create these field geometry measures at the county level were estimated using the NASS Crop Data Layer (CDL). The crop map was uploaded to ArcGIS, and various procedures were used to generate an area coverage of field polygons that allowed for the field-shape assessment. We used the field boundaries typically formed along roads, hedgerows, trees, or waterways, and all non-cropland pixels to break down the CDL into small land parcels that resembled fields rather than several parcels of land put together. Finally, a raster-to-vector conversion was performed on the remaining cropland dataset. The end result was a set of vector field boundaries at a county level.

A comparison of the survey data with data from the 2012 US Census of Agriculture (USDA, 2012) indicated the distribution of survey respondents was skewed toward those farms with larger cotton hectares planted (Figure 1). Using Lambert et al.'s (2014) approach, post-stratification survey weights were calculated to account for this difference in a way that the central tendency measures of the survey data approach the distribution of cotton farms from the 2012 Census of Agriculture.

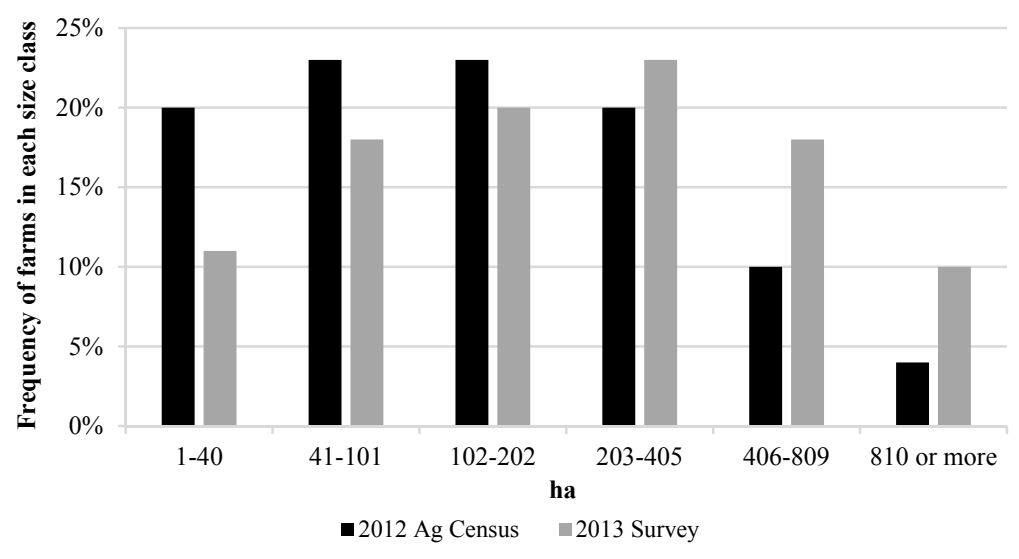

Figure 1. Cotton farm-size class (hectares) 2012 Agricultural Census vs. Survey Data

\subsection{Bivariate Probit Regression}

The adoption decisions for ASC and AG systems technologies are not mutually exclusive; thus, a farmer can adopt the two technologies simultaneously. ASC adoption does not require the previous adoption of AG systems; thus, a producer can adopt ASC without adopting AG. If a producer adopts ASC without AG systems, machinery dealers recommend using high accuracy GPS correction services such as OmniSTAR HP (Note 3), OmniSTAR XP (Note 4), JD SF2, or RTK. However, the adoption of these technologies may have a complementary relationship. This study hypothesizes that the unobserved factors influencing the decisions to adopt ASC and AG systems may be correlated. A bivariate probit regression was used to incorporate the complementarities between these two technologies and therefore the potential correlation between unobserved variables influencing the adoption decisions (Greene, 2003). A joint maximum likelihood procedure to estimate parameters associated with the ASC and AG adoption equations when unobserved variables influencing these adoption decisions are correlated is more efficient than estimating the adoption equations separately using individual probit regressions. Ignoring the potential correlation of the ASC and AG equations will result in imprecise estimations of parameters' standard errors and therefore imprecise inferences regarding the factors influencing the adoption of these two technologies (Wooldridge, 2010).

Additionally, it is hypothesized that the unobserved factors influencing the adoption of ASC and AG by farms located in the same county may be correlated; thus, the random disturbance independence assumption is relaxed using cluster-robust standard errors (Cameron \& Trivedi, 2010). Such regional grouping is important to control 
for in the estimation of the ASC equation since field geometry variables that are invariant within a county are included in this adoption equation. Ignoring the potential correlation of unobserved factors influencing the adoption equations by farms located in the same county will result in an incorrect variance-covariance matrix, leading to incorrect inferences about those variables affecting the adoption decisions.

The joint probability of adopting both technologies $\left(y_{A S C}=1\right.$ and $\left.y_{A G}=1\right)$ is,

$$
\Phi_{y_{A S C}=1 ; y_{A G}=1}=\operatorname{Prob}\left(y_{A S C}=1, y_{A G}=1 \mid x_{i A S C}, x_{i A G}\right)=\Phi\left(x_{i A S C}^{\prime} \beta_{A S C}, x_{i A G}^{\prime} \beta_{A G}, \rho\right)
$$

where, $\rho$ is the correlation between disturbances of the adoption equations described in Equations (1) and (2), and $\Phi$ is the standard normal cumulative distribution function. The null hypothesis to be tested associated with $\rho$ assumes the model consists of independent probit regressions $(\rho=0)$ and, therefore, the regressions associated with adoption of ASC technologies and AG systems can be estimated separately. If this null hypothesis is rejected, a bivariate probit regression is appropriate for evaluating the factors influencing the decisions to adopt ASC and AG systems as this approach takes into consideration the correlation between adoption equations' error terms in the estimation procedure.

The marginal probability of adopting either ASC or AG technologies can be defined as,

$$
\Phi_{y_{i j}=1}=\operatorname{Prob}\left(y_{i j}=1 \mid x_{i j}\right)=\Phi\left(x_{i j}^{\prime} \beta_{j}\right) \text { for } j=A S C, A G
$$

Given the bivariate structure of the model the marginal effects of continuous variables for the joint probability defined in Equation (4) is calculated as,

$$
\frac{\delta \Phi_{y_{i A S C}=1 ; y_{i A G}=1}}{\delta x_{i j k}}=\frac{\delta \Phi\left(x_{i A S C}^{\prime} \beta_{A S C}, x_{i A G}^{\prime} \beta_{A G}, \rho\right)}{\delta x_{i j k}}=\Phi_{y_{i A S C}=1 y_{i A G}=1} \phi_{y_{i A G}=1} \beta_{A G k}+\Phi_{y_{i A G}=1 \mid v_{i A S C}=1} \phi_{y_{i A S C}=1} \beta_{A S C k}
$$

where, the first term in Equation (6) shows the effect of one unit increase in $x_{i j k}$ on the probability of adopting AG, weighted by the probability of adopting ASC given AG has been already adopted. The second term in (6) shows the effect of one unit increase in $x_{i j k}$ on the probability of adopting ASC, weighted by the probability of adopting AG given ASC has been already adopted.

The effect of the continuous variable $x_{i j k}$ on the marginal probability of adopting ASC and AG described in Equation (5) is,

\subsection{Empirical Model}

$$
\frac{\delta \Phi_{y_{i j}=1}}{\delta x_{i j k}}=\phi\left(x_{i j}^{\prime} \beta_{j}\right) \beta_{j k} \text { for } j=A S C, A G
$$

Existing research on the adoption of PA technologies guides the consideration of variables that may influence the adoption of ASC technologies and AG systems. Variables previously identified as factors influencing the decision to adopt PA technologies include age, education, farm size, sources used to obtain PA information, and the use of best management practices (BMPs). Banerjee et al. (2008), Larson et al. (2008), Walton et al. (2008), and D'Antoni, Mishra, and Joo (2012) included age in the adoption equations and found that younger farmers with longer planning horizons were more likely to adopt PA technologies than older producers. Thus, farmer age $(A G E)$ was hypothesized to have a negative effect on the adoption of ASC technologies and AG systems.

Producer education level may influence the decision to adopt PA technologies (Banerjee et al., 2008; Larson et al., 2008; Walton et al., 2010; Lambert et al., 2014). Farmers with more education (BGDEDUCATION) are more likely to adopt PA technologies because they may have better skills to understand more complex technologies and their potential benefits.

Farm size was hypothesized to have a positive influence on the decisions to adopt ASC technologies and AG systems (D'Antoni et al., 2012; Lambert et al., 2014). A larger farm operation implies more crop area over which to spread investment costs. Farm size was hypothesized to have a positive effect on the adoption of ASC technologies and AG systems. Total crop hectares harvested (AVHA) was used as a proxy for farm size because cotton producers benefit from the use of these technologies on other crops (e.g., corn, soybeans).

Information sources used to obtain precision agriculture information can influence the adoption of PA technologies (Velandia et al., 2010). For instance, McBride and Daberkow (2003) found that information obtained from Extension personnel has a smaller impact on a producer's decision to adopt PA than information obtained from crop consultants or machinery dealers. The use of farm equipment providers to obtain PA information may be the most appropriate variable to include in both adoption equations because equipment providers distribute ASC technologies and AG systems and provide support to producers who purchase them. In contrast, crop consultants handle other issues such as map development using yield information to set 
recommendations for variable rate application. Extension agents and specialists provide research-based information regarding the economic benefits of adopting these technologies but may not be the first source producers consult when making PA technology purchasing decisions. A farm dealer variable (FARMDEALER) is included in the ASC and AG adoption equations. This variable is hypothesized to have a positive effect on the likelihood of adopting both ASC and AG technologies.

The use of Best Management Practice (BMPs) such as cover crops may positively influence the adoption of PA technologies (Lambert, Paudel, \& Larson, 2015). The use of cover crops reduce the need of herbicides and pesticides, improve soil health, enhance soil fertility, and conserve soil moisture, among other benefits. Producers using cover crops have the skill and ability needed to implement production practices aiming to increase farm profits and decrease the negative environmental impacts of agriculture. These producers will have an inclination to adopt technologies aiming to accomplish similar goals. Therefore, we hypothesized producer using cover crops will be more likely to adopt ASC technologies.

Banerjee et al. (2008) suggest the use of other PA technologies positively influence the adoption of GPS guidance system given that the marginal cost of adopting this technology is fairly low if a producer already owns other PA technologies. Additionally, given ASC was made commercially available in 2008, later than other precision farming technologies such as yield monitors, it is likely that the use of other precision farming technologies made some producers more likely to adopt ASC because of the benefits they have already experience from using other PA technologies.

Shockley et al. (2012), Velandia et al. (2013), and Larson et al. (2016) found that producers with irregularly shaped fields will experience the highest cost savings (e.g., saved seed and saved chemicals associated with overlap reduction) from the adoption of ASC technologies. Perimeter-to-area ratio (P/A) was used by Velandia et al. (2013) and Larson et al. (2016) as a measure of field geometry, where lower P/A levels represent more regularly shaped fields. Previous research suggests that $\mathrm{P} / \mathrm{A}$ positively impacts the potential input costs savings from the adoption of ASC; thus, $\mathrm{P} / \mathrm{A}$ measures were included among the field-geometry variables considered in this research. The median field $\mathrm{P} / \mathrm{A}$ ratio of all agricultural fields in a county (MEDIANIRR) was considered, as well as the modified sum of field P/A ratio per county:

$$
\text { SUMIRR }=\frac{\sum_{i=1}^{N_{c}} p_{i}}{\sum_{i=1}^{N_{c}} a_{i}}
$$

where, $p_{i}$ and $a_{i}$ are perimeter and area of field $i$ in county $c$, respectively, and $N_{c}$ is the number of fields in a specific county. The MEDIANIRR and SUMIRR are expected to be higher in counties with a larger percentage of irregularly shaped fields.

The field geometry measures presented above are expected to positively influence the likelihood of adopting ASC technologies. The natural logarithm was applied to the field geometry variables presented above (i.e., LOGMEDIANIRR and LOGSUMIRR) to simplify the interpretation of their marginal effects as the impact of a percentage change in field irregularity on the probability of adopting ASC technologies.

Because there are two different field geometry measures considered in this study, there are two bivariate probit regressions (i.e., one per measure) to be evaluated and compared. Parameter estimates from individual probit regressions are also presented and compared with the bivariate probit regressions. The Akaike Information Criterion (AIC) (Akaike, 1974) and the Bayesian Information Criterion (BIC) (Schwarz, 1978) were used to compare the two bivariate probit regressions and select the regression that best fits the data used in this study. Lower AIC and BIC values indicate a better fit between the regression approach and the data.

Multicollinearity can distort results by inflating the estimated variances (Greene, 2003). For the purpose of evaluating multicollinearity, the condition index was used to compare the models in this study (Belsley, Kuh, \& Welsch, 1980). Condition indexes between 30 and 80 are considered to be an indication of moderate to strong collinearity among covariates (Belsley, 1991).

\subsection{Predicting Adoption Rates of ASC Technologies}

As suggested in the introduction of this article, regressions' results could help machinery dealers identify the location of target clientele more likely to adopt ASC technologies. State averages were used to estimate adoption probabilities because farmer and farm business characteristics of cotton producer were only available from the 2012 USDA Census of Agriculture at the state level, and those not available were estimated using survey data, where some counties have information for only one or two farms per county. Therefore, estimated probabilities do not necessarily reflect actual probabilities of adoption because we are using state averages rather than county averages for some of the variables included in the regression models. Nonetheless, the probabilities presented 
help us understand how field geometry and other farmer and farm business characteristics influence the likelihood of adopting ASC technologies by cotton farmers.

Using the regression results, we estimated average cotton farmer probabilities of adopting ASC technologies by county for the 14 states included in this study. We only estimated adoption probabilities for those counties with at least one cotton farm as reported by the 2012 USDA Census of Agriculture. Using the estimated parameters of the ASC equation, the average age of cotton farmers and average farm size of cotton farms by state as reported in the 2012 USDA Census of Agriculture, estimated state average values of all other independent variables included in the ASC equation based on survey data, and the estimated field geometry measure by county, LOGSUMIRR, we calculated the predicted probabilities as,

$$
\begin{aligned}
& \hat{p}_{\mathrm{c}}=\mathrm{F}\left(\widehat{\beta}_{0}+\widehat{\beta}_{A V H V} \cdot \text { Size }_{s}+\widehat{\beta}_{\text {BGEDUCATION }} \cdot \text { BGDEDUCATION }_{s}+\widehat{\beta}_{A G E} \cdot A G E_{s}+\widehat{\beta}_{\text {FARMDEALER }} \cdot\right. \text { FARMDEALER } \\
& \left.+\widehat{\beta}_{\text {COVER }} \cdot \text { COVER }_{S}+\widehat{\beta}_{O P A} \cdot O P A_{S}+\widehat{\beta}_{\text {LOGSUMIRR }} \cdot \text { LOGSUMIRR }\right)
\end{aligned}
$$

where, $\hat{p}_{\mathrm{c}}$ is a vector of predicted probabilities by county; $F$ is the cumulative normal distribution; $\widehat{\beta}_{0}, \widehat{\beta}_{A V H V}$, $\widehat{\beta}_{\text {BGEDUCATION }}, \widehat{\beta}_{A G E}, \widehat{\beta}_{\text {FARMDEALER }}, \widehat{\beta}_{\text {COVER }}, \widehat{\beta}_{\text {OPA }}$, and $\widehat{\beta}_{\text {LOGSUMIRR }}$ are estimated parameters from the ASC equation; Size $_{s}$ is the average farm size, including both cotton and other crops hectares, of cotton farms by state according to the 2012 USDA Census of Agriculture; BGDEDUCATION $N_{s}$ is average percentage of producers with a bachelor or a graduate degree by state; $A G E_{s}$ is the average age of cotton farmers by state; FARMDEALER $R_{S}$ is the average percentage of producers using farm dealers to obtain precision farming information by state; COVER $_{S}$ is the average percentage of producers using cover crops by state; $O P A_{s}$ is the average percentage of producers that use or have used other PA technologies, different than ASC or AG systems, by state; and LOGSUMIRR $R_{S}$ is the logarithm of the modified sum of field perimeter-to-area ratio per county.

Average values of all variables estimated on a per state basis were held constant for all counties within a state. Given we are holding constant all variables at the state level, except for the field geometry measure variable, estimated probabilities only help us understand how field geometry influences adoption probabilities within the same state. We can also explore how other variables affect adoption probabilities as these variables change across states. Nonetheless, it is important to notice accuracy of the estimated probabilities by county presented in this study are affected by the assumption that all counties within a state have the same values for all variables included in the adoption equation except for the field geometry measure.

\section{Results and Discussion}

\subsection{Descriptive Statistics}

Table 1 presents variable definitions and descriptive statistics for the 1,435 observations that were included in the regression analysis after eliminating those with missing values. The average crop hectares harvested between 2011 and 2012 were 395 hectares and $35 \%$ of producers had used cover crops on their fields. The average age of producers was 57 years; $58 \%$ had used farm dealers to obtain PA information; and $41 \%$ had a bachelors or graduate degree. About $31 \%$ of respondents had adopted ASC technologies and $59 \%$ had adopted AG systems. Field geometry measures were estimated at the county level.

Table 2 presents the distribution of field geometry measure SUMIRR by P/A ratio category. The percentages presented in Table 2 suggest there is a good representation of the various types of fields based on this field geometry measure. Examples of two types of fields (i.e., SUMIRR $<0.01$ and SUMIRR $>0.03$ ) are presented in Figure 2

Previous studies suggest a $1 \%$ increase in the perimeter-to-area ratio could result in a significant increase in overlapped area within a field and therefore an increase in overlapping applications of inputs (Velandia et al., 2013; Larson et al., 2016). 
Table 1. Summary statistics of variables used in regressions $(n=1435)$

\begin{tabular}{|c|c|c|c|c|c|}
\hline Variables & Description & Mean & $\begin{array}{l}\text { Standard } \\
\text { Deviation }\end{array}$ & Min & Max \\
\hline \multicolumn{6}{|c|}{ A. Dependent variables: } \\
\hline ASC & $\begin{array}{l}=1 \text { if producer has adopted } \\
\text { ASC for planters or sprayers }\end{array}$ & 0.31 & & 0 & 1 \\
\hline AG & $\begin{array}{l}=1 \text { if producer has adopted } \\
\text { AG auto-guidance systems }\end{array}$ & 0.59 & & 0 & 1 \\
\hline \multicolumn{6}{|c|}{ B. Independent variables: } \\
\hline$A V H A$ & $\begin{array}{l}\text { Average crop hectares harvested between } \\
2011 \text { and } 2012 \text {, divided by } 100\end{array}$ & 3.95 & 5.37 & 0.01 & 70.82 \\
\hline BGDEDUCATION & $\begin{array}{l}=1 \text { if the producer's highest level of } \\
\text { education is a bachelors or graduate degree }\end{array}$ & 0.41 & & 0 & 1 \\
\hline$A G E$ & Age of primary decision maker as of 2014 & 56.83 & 13.30 & 20 & 100 \\
\hline FARMDEALER & $\begin{array}{l}=1 \text { if the producer has used a farm dealer as a } \\
\text { source of information about precision farming }\end{array}$ & 0.58 & & 0 & 1 \\
\hline COVER & $=1$ if the producer uses cover crops, 0 otherwise & 0.35 & & 0 & 1 \\
\hline OTHER_TECH & $\begin{array}{l}=1 \text { if the producer uses other PA technologies } \\
\text { different than ASC or AG systems, } 0 \text { otherwise }\end{array}$ & 0.47 & & 0 & 1 \\
\hline SUMIRR & $\begin{array}{l}\text { The sum of the perimeter-to-area ratio of } \\
\text { the county a producer operates within }\end{array}$ & 0.01 & 0.01 & 0.00 & 0.05 \\
\hline MEDIANIRR & $\begin{array}{l}\text { The median of the perimeter-to-area ratio of } \\
\text { the county a producer operates within }\end{array}$ & 0.03 & 0.01 & 0.00 & 0.06 \\
\hline
\end{tabular}

Table 2. Distribution of field geometry measure SUMIRR

\begin{tabular}{lll}
\hline P/A Ratio Category & No. of observations & Percent of total observation \\
\hline SUMIRR $\leq 0.01$ & 728 & $50.73 \%$ \\
$0.01<$ SUMIRR $\leq 0.02$ & 499 & $34.77 \%$ \\
SUMIRR $>0.02$ & 208 & $14.49 \%$ \\
\hline
\end{tabular}
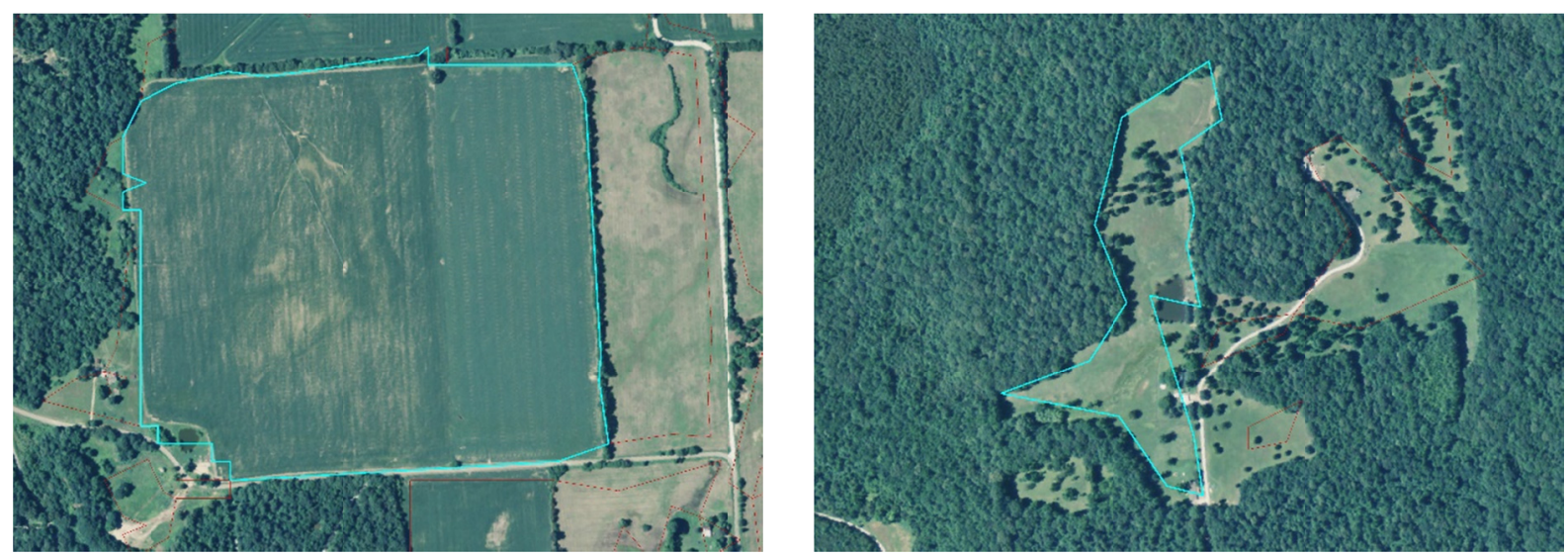

Figure 2. Field with SUMIRR $<0.01$ (left) and field with SUMIRR $>0.02$ (right)

Table 3 and Table 4 present comparisons of operator and farm business characteristics, and the field geometry measures for ASC and AG systems adopters and non-adopters. Results suggest that adopters of ASC technologies are younger and have achieved higher levels of education on average, with $48 \%$ having a bachelors or graduate degree compared to $39 \%$ of non-adopters having that level of education (Table 3 ). 
Table 3. Means of the explanatory variables included in the ASC adoption regression by ASC adoption status

\begin{tabular}{|c|c|c|}
\hline Variable & $\mathrm{ASC}=1$ & $\mathrm{ASC}=0$ \\
\hline$A V H A * * *$ & 6.14 & 2.99 \\
\hline BGDEDUCATION *** & 0.48 & 0.39 \\
\hline$A G E^{* * *}$ & 52.34 & 58.80 \\
\hline COVER $* * *$ & 0.40 & 0.32 \\
\hline FARMDEALER*** & 0.78 & 0.50 \\
\hline OTHER_TECH*** & 0.80 & 0.32 \\
\hline SUMIRR & 0.01 & 0.01 \\
\hline$A G^{* * *}$ & 0.94 & 0.44 \\
\hline
\end{tabular}

Note. $* * *$, and $* * *$ represent statistically different means between adopter and non-adopters at the $10 \%, 5 \%$, and $1 \%$ levels, respectively.

Average crop hectares harvested were 614 and 299 for ASC adopters and non-adopters, respectively, suggesting that adopters have larger farm operations than non-adopters. Results also suggest that ASC adopters are more likely to use farm dealers to obtain information about PA technologies and use cover crops than non-adopters. Finally, $94 \%$ of cotton producers who adopted ASC technologies also adopted AG systems, compared to $44 \%$ of ASC non-adopters who had adopted AG systems.

Table 4. Means of the explanatory variables included in the AG adoption regression by AG adoption status

\begin{tabular}{|c|c|c|}
\hline Variables & $\mathrm{AG}=1$ & $\mathrm{AG}=0$ \\
\hline$A V H A^{* * *}$ & 5.09 & 2.29 \\
\hline$B G D E D U C A T I O N^{* * *}$ & 0.46 & 0.35 \\
\hline$A G E^{* * *}$ & 54.97 & 59.57 \\
\hline FARMDEALER*** & 0.67 & 0.46 \\
\hline OTHER_TECH*** & 0.62 & 0.25 \\
\hline$A S C(\%)^{* * *}$ & 0.48 & 0.04 \\
\hline
\end{tabular}

Note. $* * *$, and $* * *$ represent statistically different means between adopter and non-adopters at the $10 \%, 5 \%$, and $1 \%$ levels, respectively.

Similar to ASC adopters, AG adopters are younger and have achieved higher levels of education than non-adopters. About $46 \%$ of adopters have a bachelors or graduate degree compared to $35 \%$ of non-adopters (Table 4). In addition, AG adopters harvest more crop hectares and are more likely to use farm dealers for information about PA technologies than non-adopters. Lastly, about $48 \%$ of AG systems adopters also use ASC technologies, while only about $4 \%$ of the AG systems non-adopters use ASC technologies.

\subsection{Bivariate Probit Regression Results and Discussion}

The correlation coefficient associated with residuals $(\rho)$ from both adoption equations, ASC technologies and AG systems, was positive and statistically significant at the $1 \%$ level for all evaluated regressions, supporting the hypothesis that the error terms in the ASC and AG equations are correlated. Therefore, a bivariate probit-regression approach was appropriate for this analysis. This approach supports the hypothesis of the complementary relationship between these technologies and therefore incorporates this information into the parameter estimates associated with both adoption equations.

The model-selection results from the three bivariate probit regressions evaluated in this study (e.g., no field geometry measure, SUMIRR, MEDIANIRR included in the ASC adoption equation) are reported in Table 5. The $\mathrm{AIC}$ and BIC values were smallest for the bivariate probit regression that included LOGSUMIRR, suggesting that this field geometry measure is the most appropriate for this analysis. Results from the bivariate probit regression that included LOGSUMIRR as a measures of field shape irregularity are presented in Table 6. Parameter estimates from individual probit regressions are also included in Table 6 for comparison purposes. Given that the error terms from both adoption equations are correlated, as suggested above, the joint maximum likelihood procedure used by the bivariate probit regression approach is a more efficient procedure for estimating the parameters associated with each variable included in the regression model (Wooldridge, 2010). 
Table 5. Goodness of fit measures for all regression models

\begin{tabular}{llllll}
\hline Shape Variable & Sign & AIC & BIC & Log-Likelihood & Condition Index \\
\hline No & & 41321.57 & 41395.33 & -20646.78 & 14.54 \\
LOGMEDIANIRR & $(+)$ & 41322.22 & 41401.25 & -20646.11 & 27.39 \\
LOGSUMIRR & $(+)$ & 41263.29 & 41342.32 & -20616.64 & 28.23 \\
\hline
\end{tabular}

The marginal effects for the joint probability of adopting both ASC and AG and marginal probabilities of adopting either ASC or AG are presented in Table 7.

Results suggest that the farm business characteristics related to farm size $(A V H A)$ and field geometry (LOGSUMIRR) positively influence the joint probability of adopting ASC and AG. Producers with an additional 100 hectares of cropland harvested were $2 \%$ more likely to adopt both ASC and AG, and a $1 \%$ increase in SUMIRR increases the likelihood of jointly adopting ASC and AG by $3 \%$.

Producer characteristics influencing the probability of jointly adopting ASC technologies and AG systems include education level (BGDEDUCATION), age of producer $(A G E)$, the use of farm dealers to gather information about PA technologies (FARMDEALER), and use other PA technologies (OTHER_TECH). Producers with a bachelors or graduate degree were more likely to adopt both ASC technologies and AG systems (Table 7). Consistent with previous literature, older producers were less likely to jointly adopt ASC and AG systems. Finally, the use of farm dealers to obtain PA information increased the probability of jointly adopting ASC technologies and AG systems by $12 \%$. Finally, those producers who have already adopted other PA technologies are about $28 \%$ more likely to adopt both ASC technologies and AG systems. The signs of all variables were consistent with the hypothesized sign values.

The marginal effects associated with the likelihood of adopting only ASC or AG technologies were also evaluated. Similar to the results presented above older producers, who are more educated, use farm dealers to obtain PA information, and with larger harvested acreage are more likely to adopt ASC technologies and AG systems. Additionally, farms located in counties with more irregularly shaped farm fields are more likely to adopt ASC technologies. Specifically, a 1\% increase in SUMIRR increase the likelihood of adopting ASC technologies by about $4 \%$.

Table 6. Parameter Estimates for the ASC and AG adoption equations from a bivariate probit and probit regressions with LOGSUMIRR and cluster robust standard errors included $(n=1435)$

\begin{tabular}{|c|c|c|c|c|}
\hline \multirow[t]{2}{*}{ Independent Variables ${ }^{\mathrm{a}}$} & \multicolumn{2}{|c|}{$\begin{array}{l}\text { Parameter Estimates for the } \\
\text { Bivariate Probit Model }\end{array}$} & \multicolumn{2}{|c|}{$\begin{array}{l}\text { Parameter Estimates for the } \\
\text { Individual Probit Models }\end{array}$} \\
\hline & ASC & $\mathrm{AG}$ & ASC & $\mathrm{AG}$ \\
\hline Constant & $-0.4429\left(0.4162^{\mathrm{a}}\right)$ & $-0.0214(0.2009)$ & $-1.6383 * * *(0.4226)$ & $-0.0359(0.2039)$ \\
\hline$A V H A$ & $0.0563 * * *(0.0114)$ & $0.0910 * * *(0.0148)$ & $0.0491 * * *(0.0106)$ & $0.0983 * * *(0.0159)$ \\
\hline BGDEDUCATION & $0.2513 * * *(0.0905)$ & $0.2577 * * *(0.0852)$ & $0.2231 * *(0.0935)$ & $0.2733 * * *(0.0859)$ \\
\hline$A G E$ & $-0.0122 * * *(0.0030)$ & $-0.0095 * * *(0.0029)$ & $-0.0131 * * *(0.0031)$ & $-0.0096 * * *(0.0029)$ \\
\hline FARMDEALER & $0.4674 * * *(0.0915)$ & $0.2034 * *(0.0826)$ & $0.4756 * * *(0.0937)$ & $0.2053 * *(0.0824)$ \\
\hline COVER & $0.1312(0.0867)$ & & $0.1736 * *(0.0955)$ & \\
\hline OTHER_TECH & $0.9862 * * *(0.0916)$ & $0.7636 * * *(0.0891)$ & $1.0178 * * *(0.0915)$ & $0.7705 * * *(0.0894)$ \\
\hline LOGSUMIRR & $0.1428 *(0.0835)$ & & $-0.1213(0.0881)$ & \\
\hline$n$ & 1435 & & 1435 & 1435 \\
\hline Log pseudo-likelihood value & -20616.6440 & & -9377.9280 & -12558.3150 \\
\hline Wald $\chi^{2}(12)$ & $413.03^{* * *}$ & & $297.59 * * *$ & $203.13^{* * *}$ \\
\hline Correlation coefficient & $0.6990^{* * *}$ & & & \\
\hline
\end{tabular}

Note. ${ }^{a}$ Numbers in parenthesis are robust standard errors. $*$, **, and $* * *$ represent statistical significance at $10 \%$, $5 \%$, and $1 \%$ levels, respectively.

Overall, results from the bivariate regression presented above indicate that adopters of ASC and AG were likely to be younger, more educated, harvest more crop hectares, and use farm dealers as a PA information source than non-adopters. As hypothesized, farm operations located in counties that were more likely to have fields with higher levels of shape irregularity may be more likely to adopt ASC technologies. 
Table 7. Marginal effects on ASC and AG adoption probabilities from bivariate probit model

\begin{tabular}{llll}
\hline & $\mathrm{ASC}=1, \mathrm{AG}=1$ & $\mathrm{ASC}=1$ & $\mathrm{AG}=1$ \\
\hline AVHA & $0.0166^{* * *}\left(0.0028^{\mathrm{a}}\right)$ & $0.0158^{* * *}(0.0031)$ & $0.0353 * * *(0.0057)$ \\
BGDEDUCATION & $0.0706^{* * *}(0.0237)$ & $0.0713^{* * *}(0.0261)$ & $0.0994 * * *(0.0326)$ \\
AGE & $-0.0033^{* * *}(0.0008)$ & $-0.0034 * *(0.0009)$ & $-0.0037 * *(0.0011)$ \\
FARMDEALER & $0.1188^{* * *}(0.0232)$ & $0.1287 * * *(0.0249)$ & $0.0789 * *(0.0321)$ \\
COVER & $0.0326(0.0219)$ & $0.0375(0.0252)$ & \\
OTHER_TECH & $0.2808^{* * *}(0.0269)$ & $0.2906 * * *(0.0285)$ & $0.2849 * * *(0.0318)$ \\
LOGSUMIRR & $0.0349 *(0.0207)$ & $0.0399 *(0.0234)$ & \\
\hline Predicted Probability & 0.1879 & 0.1997 & 0.5922
\end{tabular}

Note. ${ }^{a}$ Numbers in parenthesis are robust standard errors. *, **, and *** represent statistical significance at $10 \%$, $5 \%$, and $1 \%$ levels, respectively.

\subsection{Predicting Adoption Rates of ASC Technologies}

A graphic representation of the estimated ASC adoption probabilities is presented in Figure 3. This map suggests cotton farmers with operations in eastern Arkansas, western Tennessee, and a couple of counties in middle Tennessee are more likely to adopt ASC technologies. Our regression results suggest the use of other PA technologies and farm dealers as a source of precision farming information have the largest impact on the probability of adopting ASC by cotton farmers, and the survey data indicate that these two states have two of the highest percentages of users of other PA technologies and farm dealers to obtain PA information. Additionally, although Tennessee does not have the highest percentage of farm dealers' users it has, on average, the highest value of SUMIRR per county. Adoption probabilities within each state vary based on county-level field geometry. As expected, farmers with operations in counties with higher field irregularity (higher LOGSUMIRR) have higher probabilities of ASC adoption.

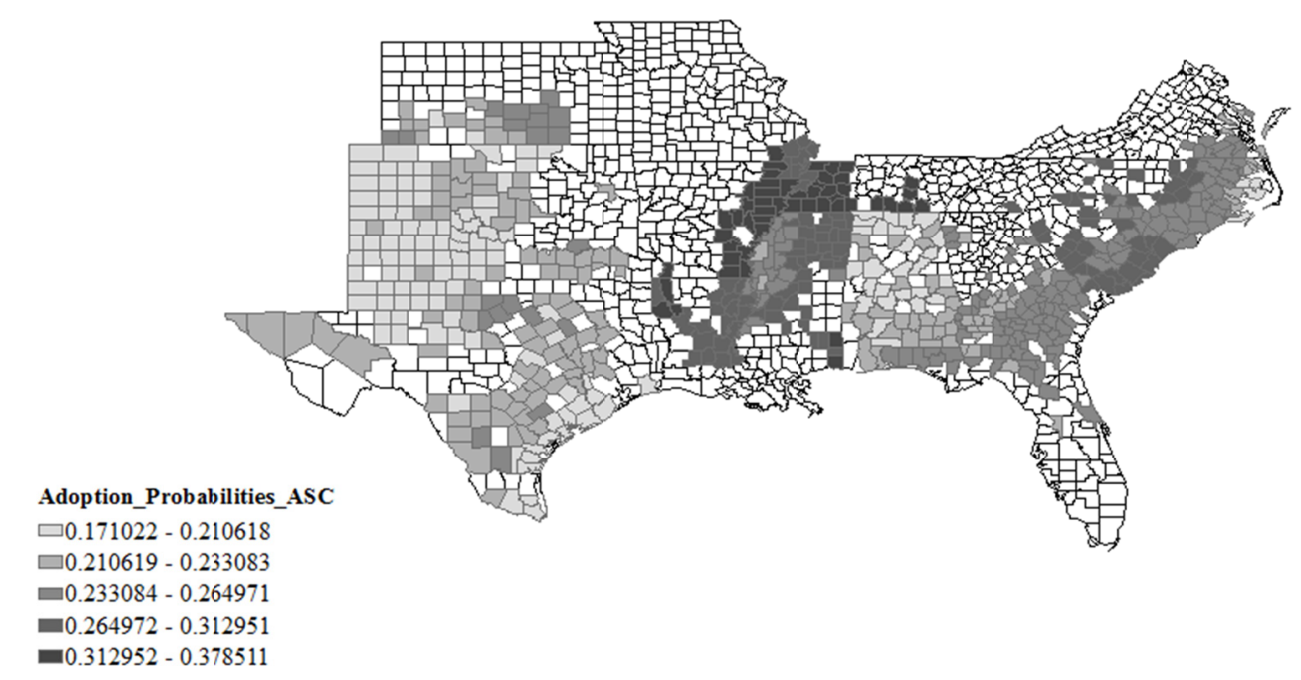

Figure 3. Estimated probability of adoption of ASC technologies by county based on regression results

\section{Summary and Implications}

The results from the present study showed that precision agriculture technologies such as ASC and AG would continue to be adopted by producers in the United States as fertilizer, chemical and seed costs, which represent $45 \%, 70 \%$ and $76 \%$ of total operating costs for cotton, soybean, and corn, respectively (USDA-ERS, 2018), increase. Technologies like the ones evaluated in this study (ASC technologies and GPS guidance systems) that result in both monetary and time savings may have an advantage, specifically for larger farms. A bivariate-probit regression approach was used to evaluate the adoption of ASC technologies and AG systems. The findings from this study have helped to improve our understanding about the factors that could influence the adoption of the 
evaluated technologies, such as farmer age, education, the use of farm dealers as a source of PA information, the use of other PA technologies, farm size, and field geometry.

A producer's decision to adopt ASC technologies and AG systems is influenced by farmer and farm business characteristics. These include crop hectares harvested, farmer age, educational attainment, and the use of farm dealers to obtain PA information. Producers who are older are less likely to adopt ASC or AG, which follows the hypothesis that these producers have shorter planning horizons than younger producers and are, therefore, less likely to make changes in their production systems. Additionally, consistent with previous literature (Martin et al., 2007; Banerjee et al., 2008; Velandia et al., 2013), producers with larger farms are more likely to adopt ASC and AG due to their ability to spread the cost of the technology across more hectares.

It is important to note that using farm dealers as a source of PA information has the second greatest impact, after adoption of other PA technologies, on the adoption of ASC technologies. This result may reflect the effectiveness of farm dealers in persuading producers to adopt PA technologies, but may also imply more informed producers are making better decisions for their farms. Consistent with the latter implication, education has the third highest effect on adoption probabilities, implying that a combination of higher levels of education (i.e., bachelors or graduate degree) with good information may help producers better understand the benefits of adopting ASC technologies. Additionally, more informed producers who are able to process complex information, may be more inclined to adopt these technologies in counties with more irregularly shaped fields. Although farm size and age influence ASC adoption decisions, their influence seems to be less important than the use of farm dealers as a source of PA information and field geometry.

Though results from this study suggest farms located in counties with more irregularly shape fields are more likely to adopt ASC technologies, the variable used in this analysis to measure field geometry should be used with caution. The lack of farm-level data on field geometry led to the creation of field geometry measures using the CDL data. This approach was not validated by matching fields obtained from the CDL data with actual field data from individual farms because these data were not available. Until the procedure used in this study to create the field geometry measures is validated, SUMIRR should be used with caution when evaluating field geometry at the farm-level. On the other hand, in the absence of field geometry information at the farm level, SUMIRR may be the best measure of field geometry when evaluating the likelihood of farms in a specific region to adopt and benefit from ASC technologies.

\section{Acknowledgements}

This research was funded by Cotton Incorporated and the agricultural research institutions at the University of Florida, Louisiana State University, Mississippi State University, North Carolina State University, University of Tennessee, and Texas Tech University.

\section{References}

Akaike, H. (1974). A new look at the statistical model identification. IEEE Transactions on Automatic Control, 19(6), 716-723. https://doir.org/ 10.1109/TAC.1974.1100705

Banerjee, S., Martin, S. W., Larkin, S. L., Marra, M. C., Paxton, K. W., Roberts, R. K., ... Reeves, J. M. (2008). A binary logit estimation of factors affecting adoption of GPS guidance systems by cotton producers. Journal of Agricultural and Applied Economics, 40(1), 345-355. https://doi.org/10.1017/S107407080 0028157

Batte, M. T., \& Ehsani, M. R. (2006). The economics of precision guidance with auto-boom control for agricultural sprayers. Computers \& Electronics in Agriculture, 53(1), 28-44. https://doi.org/10.1016/ j.compag.2006.03.004

Belsley, D. A. (1991). A guide to using the collinearity diagnostics. Computer Science in Economics and Management, 4(1), 33-50. https://doi.org/10.1007/BF00426854

Belsley, D. A., Kuh, E., \& Welsch, R. E. (1980). Regression diagnostics: Identifying influential data and sources of collinearity. New York, NY: John Wiley \& Sons. https://doi.org/10.1002/0471725153

Cameron, A. C., \& Trivedi, P. K. (2010). Microeconometrics using Stata. College Station, TX: Stata Press.

D’Antoni, J. M., Mishra, A. K., \& Joo, H. (2012). Farmers' perception of precision technology: The case of autosteer adoption by cotton farmers. Computers and Electronics in Agriculture, 87, 121-128. https://doi.org/10.1016/j.compag.2012.05.017

Dillman, A. (2000). Mail and Internet surveys: The tailored design method (2nd ed.). New York, NY: John Wiley \& Sons, Inc. 
Edge, B. (2016). Factors influencing the adoption of automatic section control technologies and GPS auto-guidance systems in cotton production (Master's thesis, University of Tennessee, Knoxville, Tennessee, USA). Retrieved from http://trace.tennessee.edu/cgi/viewcontent.cgi?article $=5133 \&$ context=utk_gradthes

Fulton, J., Mullenix, D., Brooke, A., Winstead, A., \& Ortiz, B. (2011). Automatic section control (ASC) technology for row crop planters. Precision Agriculture Series: Timely Information, Agriculture, Natural Resources \& Forestry, Alabama Cooperative Extension Service, Auburn, AL, USA. Retrieved from http:/www.aces.edu/pubs/docs/A/ANR-2217/ANR-2217.pdf

Greene, W. H. (2003). Econometric analysis (5th ed.). Upper Saddle, NJ: Prentice Hall.

Jara-Rojas, R., Bravo-Ureta, B. E., Engler, A., \& Díaz, J. (2013). An analysis of the joint adoption of water conservation and soil conservation in central Chile. Land Use Policy, 32, 292-301. https://oi.org/10.1016/ j.landusepol.2012.11.001

Lambert, D. M., English, B. C., Harper, D. C., Larkin, S. L., Larson, J. A., Mooney, D. F., ... Reeves, J. M. (2014). Adoption and frequency of precision soil testing in cotton production. Journal of Agricultural and Resource Economics, 39(1), 106-123. Retrieved from http:/www.waeaonline.org/UserFiles/file/JAREApr 20147Lambertpp106-123.pdf

Lambert, D. M., Paudel, K. P., \& Larson, J. A. (2015). Bundled adoption of precision agriculture technologies by cotton producers. Journal of Agricultural and Resource Economics, 40(2), 325-345. Retrieved October 9, 2017, from https://ageconsearch.umn.edu/bitstream/206599/2/JAREMay20158Lambertpp325-345.pdf

Larson, J. A., Velandia, M., Buschermohle, M. J., \& Westlund, S. M. (2016). Effect of field geometry on profitability of automatic section control for chemical application equipment. Precision Agriculture, 17(1), 18-35. https://doi.org/10.1007/s11119-015-9404-y

Larson, J. A., Roberts, R. K., English, B. C., Larkin, S. L., Marra, M. C., Martin, S. W., ... Reeves, J. M. (2008). Farmer adoption of remotely sensed imagery for precision management in cotton production. Precision Agriculture, 9(4), 195-208. https://doi.org/10.1007/s11119-008-9065-1

Martin, S. W., Banerjee, S., Reeves, J. M., Roberts, R. K., English, B. C., Larson, J. A., ... Reeves, J. M. (2007). Revealed characteristics of guidance systems adopters in cotton production. Crop Management, 6(1). https://doi.org/10.1094/CM-2007-1116-01-RV

McBride, W. D., \& Daberkow, S. G. (2003). Information and the adoption of precision farming technologies. Journal of Agribusiness, 21(1), 21-28. Retrieved from http://ageconsearch.umn.edu/record/14671/files/ 21010021.pdf

McDonald, G. (2015). Tennessee row crop farmer. Personal communication.

McFadden, D. (1974). Frontiers in econometrics, economic theory and mathematical economics. New York, NY: Academic Press.

National Research Council. (1997). Precision agriculture in the 21st century: Geospatial and information technologies in crop management. Washington DC: National Academy Press.

Rahm, M., \& Huffmann, W. (1984). The adoption of reduced tillage: The role of human capital and other variables. American Journal of Agricultural Economics, 66(4), 405-413. https://doi.org/10.2307/1240918

Roberts, R. K., English, B. C., Larson, J. A., Cochran, R. L., Goodman, W. R., Larkin, S. L., ... Reeves, J. M. (2004). Adoption of site-specific information and variable-rate technologies in cotton precision farming. Journal of Agricultural and Applied Economics, 36(1), 143-158. https://doi.org/10.1017/S107407080 $002191 \mathrm{X}$

Schwarz, G. (1978). Estimating the dimension of a model. Annals of Statistics, 6(2), 461-464. https://doi.org/ $10.1214 / \mathrm{aos} / 1176344136$

Shockley, J. M., Dillon, C. R., \& Stombaugh, T. S. (2011). A whole farm analysis of the influence of auto-Steer navigation on net returns, risk, and production practices. Journal of Agricultural and Applied Economics, 43(1), 57-75. https://doi.org/10.1017/S1074070800004053

Shockley, J. M., Dillon, C. R., Stombaugh, T., \& Shearer, S. (2012). Whole farm analysis of automatic section control for agricultural machinery. Precision Agriculture, 13(4), 411-420. https://doi.org/10.1007/ s11119-011-9256-z 
Smith, C. M., Dhuyvetter, K. C., Kastens, T. L., Kastens, D. L., \& Smith, L. M. (2013). Economics of Precision Agricultural Technologies across the Great Plains. Journal of the American Society of Farm Managers and Rural Appraisers, 76, 185-206.

USDA (U.S. Department of Agriculture). (2012). 2012 Census of agriculture. Washington, DC: U.S. Department of Agriculture, National Agricultural Statistics Service. Retrieved November 20, 2017, from https://www.agcensus.usda.gov/Publications/2012/Full_Report/Volume_1,_Chapter_1_State_Level

USDA-ERS (U.S. Department of Agriculture, Economic Research Service). (2018). Commodity Costs and Returns. Retrieved May 2, 2018, from https://www.ers.usda.gov/data-products/commodity-costsand-returns

Velandia, M., Lambert, D. M., Jenkins, A., Roberts, R. K., Larson, J. A., English, B. C., ... Martin, S. W. (2010). Precision farming information sources used by cotton farmers and implications for Extension. Journal of Extension, 48(5), 1-7. Retrieved from https://www.joe.org/joe/2010october/rb6.php

Velandia, M., Buschermohle, M. J., Larson, J. A., Thompson, N., \& Jernigan, B. (2013). The economics of automatic section control technology for planters: A case study of middle and west Tennessee farms. Computers and Electronics in Agriculture, 95, 1-10. https://doi.org/10.1016/j.compag.2013.03.006

Velandia, M., Edge, B., Boyer, C., Larson, J., Lambert, D., Wilson, B., ... English, B. (2016). Factors influencing the adoption of automatic section control technologies and GPS auto-guidance systems in cotton production. Paper presented at the 2016 Agricultural and Applied Economics Association annual meeting, Boston, MA, USA. Retrieved from https://ageconsearch.umn.edu/bitstream/235563/2/Edge_B_ AEAA\%20Manuscript_Boston_2016_webversion.pdf

Walton, J. C., Lambert, D. M., Roberts, R. K., Larson, J. A., English, B. C., Larkin, S. L., ... Reeves, J. M. (2008). Adoption and abandonment of precision soil sampling in cotton production. Journal of Agricultural and Resource Economics, 33(3), 428-448. Retrieved October 10, 2017, from https://ageconsearch.umn.edu/ bitstream/46556/2/Walton.pdf

Walton, J. C., Roberts, R. K., Lambert, D. M., Larson, J. A., English, B. C., Larkin, S. L., ... Reeves, J. M. (2010). Grid soil sampling adoption and abandonment in cotton production. Precision Agriculture, 11(2), 135-147. https://doi.org/10.1007/s11119-009-9144-y

Wooldridge, J. M. (2010). Econometric analysis of cross section and panel data. Cambridge, MA: MIT Press.

Zhou, X., English, B. C., Boyer, C., Roberts, R. K., Larson, J. A., Lambert, D. M., ... Reeves, J. M. (2015). Precision Farming by Cotton Producers in Fourteen Southern States (Research Series 15-001). Department of Agricultural and Research Economics at University of Tennessee, Knoxville. Retrieved October 1, 2017, from https://ag.tennessee.edu/arec/Documents/publications/CottonSurveyReport_Sept2015.pdf

\section{Notes}

Note 1. Preliminary versions of this article are available online as a Master's thesis (Edge, 2016) and a paper presented at the 2016 Agricultural and Applied Economics Association annual meeting (Velandia et al., 2016).

Note 2. You can find the Automatic Section Control for Planters Cost Calculator at https://ag.tennessee.edu/arec/ Pages/decisionaidtools.aspx

Note 3. For information about this correction service visit: http://www.omnistar.com/SubscriptionServices/ OmniSTARHP.aspx

Note 4. For information about this correction service visit: http://www.omnistar.com/SubscriptionServices/ OmniSTARXP.aspx

\section{Copyrights}

Copyright for this article is retained by the author(s), with first publication rights granted to the journal.

This is an open-access article distributed under the terms and conditions of the Creative Commons Attribution license (http://creativecommons.org/licenses/by/4.0/). 